\title{
Moving Urban Adaptation Forward in the Great Lakes Region: Lessons Learned from the Great Lakes Adaptation Assessment for Cities
}

\author{
ASHLEE JENSEN GRACE ${ }^{1}$, ELIZABETH GIBBONS ${ }^{1 *}$, \\ JOHN CALLEWAERT ${ }^{2}$ \\ Volume 3, Spring 2015 \\ http://dx.doi.org/10.3998/mjs.12333712.0003.002 \\ ${ }^{1}$ Climate Center, Graham Sustainability Institute, University of Michigan, 717 E. Huron St., \\ Suite 2E, Ann Arbor, MI 48104 \\ 2Integrated Assessment Center, Graham Sustainability Institute, University of Michigan, \\ 625 E. Liberty St., Suite 300, Ann Arbor, MI, 48104 \\ *Corresponding author: Elizabeth Gibbons, elzrenc@umich.edu
}

\section{ABSTRACT}

Across the Great Lakes region, climate variability and change pose major risks to public finances, urban economies, health, safety, and quality of life. The negative impacts of climate change will be unevenly and unequally distributed across the region and across communities; thus, solutions must take into account socioeconomic differences, variations in the vulnerability of different populations, and the distribution of available resources. To craft smart responses, cities require placebased information that accounts for both climate variability and climate change, as well as the geographic, social, environmental, and economic conditions contributing to vulnerabilities. Working with mid-sized cities across the region, the Great Lakes Adaptation Assessment for Cities (GLAA-C), an integrated assessment of the University of Michigan Graham Sustainability Institute (Graham), piloted an approach to address these climate risks and deliver locally relevant climate adaptation resources and strategies. Over the course of the three-year GLAA-C project, Graham staff worked closely with six cities with climatic, social, and economic diversity: Toledo and Dayton, Ohio; Kingston and Thunder Bay, Ontario; and Flint 
and Ann Arbor, Michigan. Engagement with these cities led to the identification of key resources needed for adaptation and an effective process for introducing these resources to empower stakeholder action and build trust between the climate data end-users and producers. This paper explains how the GLAA-C project adopted the integrated assessment model to build a flexible approach to addressing adaptation. It also describes the key lessons learned through engagement with the six cities, and identifies opportunities for scaling these lessons throughout and beyond the Great Lakes region. These lessons now inform the ongoing Urban Adaptation Program of the University of Michigan Climate Center, a recently formed center within the Graham Sustainability Institute.

\section{Introduction}

Climate variability and change pose major risks to public finances, urban economies, and the health, safety, and quality of life of people around the world. Negative impacts of climate change are unevenly and unequally distributed across regions and communities, as disparities in wealth, employment opportunities, and available resources make certain demographics and socioeconomic groups more vulnerable. Populations that tend to be impacted the most are the elderly, the infirm, the poor, children, minorities, and marginalized populations (Altman 2012). To craft smart responses, communities need place-based information that accounts for climate variability and climate change, as well as the geographic, social, environmental, and economic conditions contributing to vulnerabilities.

Responding to climate change demands integration across social, natural, and political-science disciplines and the development of active exchanges and connections between decision makers and researchers. Without integrative science and an improved understanding of climate change, decisions cannot be based on the best available evidence. Without mechanisms to translate an improved scientific understanding into policy and management options, scientific advances are destined to irrelevance; without engagement with a wide group of stakeholders, options and strategies cannot be well-vetted prior to implementation.

The integrated assessment (IA) model offers an effective way to frame and guide decisions for sustainability problems that lack consensus on the cause or solution. Through an innovative approach to analysis that includes engaging representatives from a wide range of impacted sectors and perspectives on a given issue, IA participants collaboratively define problems, address diverse perspectives, use and share 


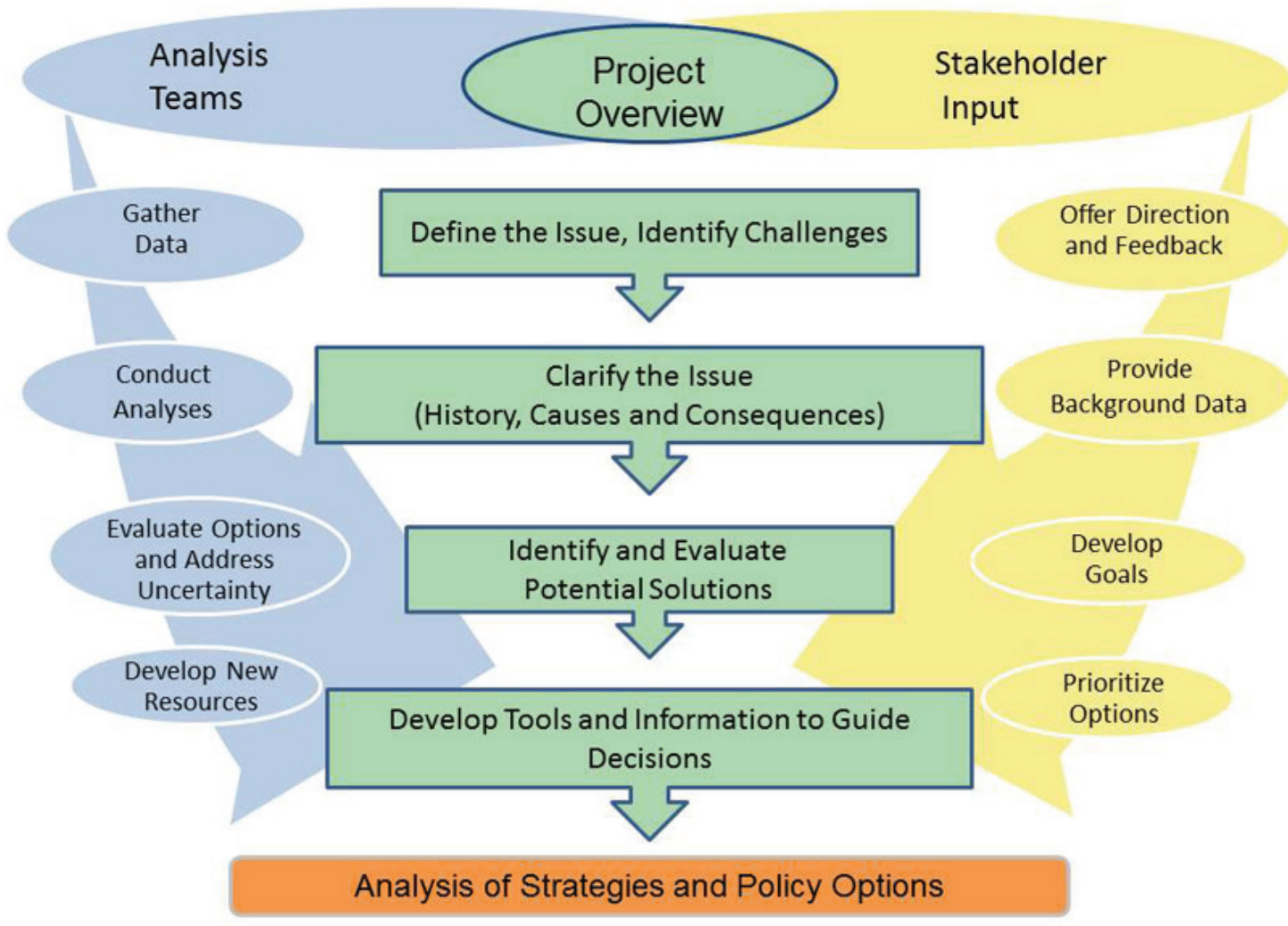

Figure 1. An IA combines sound science and collaboration with diverse stakeholders to reframe a key issue and develop feasible solutions that promote environmental and economic sustainability. Source: http://graham.umich.edu/knowledge/ia/methodology

best available information, and establish local and embedded partnerships to analyze options for bringing about positive change. Figure 1 illustrates how the input of both analytical technical experts and engaged stakeholders is necessary to ensure the best possible outcomes. Participant-identified benefits of IA include generating analytical reports and supporting data, modifying perspectives, creating new partnerships, changing processes, and leveraging additional resources (Lund et al. 2011).

In addition to a multi-stakeholder approach to confronting the challenges of climate change, communication of usable climate knowledge is central to transformative action on climate adaptation. Decision makers often highlight the need for place-based climate science and options for responding to impacts (Bidwell, Dietz, and Scavia 2013). While science-policy models to address societal problems have evolved rapidly, there is a persistent gap between the production and the use 
of scientific knowledge (Kirchoff, Lemos, and Desai 2013). To address this gap, the University of Michigan's Graham Sustainability Institute (Graham) works with boundary organizations ${ }^{1}$ (watershed councils, municipalities, private-sector organizations, non-governmental organizations) to encourage more broad dissemination and use of climate information (Dilling and Lemos200; Guston 2001). Cities are key actors among boundary organizations due to their unique responsibility to address vulnerable populations, their democratic mandate to address the concerns of their populations, and their ability to act in partnership with private-sector actors and civil society (Bulkeley 2013; Rosenzweig et al. 2011).

To assist cities throughout the Great Lakes region in their adaptation efforts, Graham piloted the Great Lakes Adaptation Assessment for Cities (GLAA-C), a project that implemented an integrated assessment framework and utilized the boundary-organization approach to achieve this goal. GLAA-C engaged six partner cities: Kingston and Thunder Bay, Ontario; Dayton and Toledo, Ohio; and Ann Arbor and Flint, Michigan. With three years of funding from the Kresge Foundation and the Graham Sustainability Institute (2011-2014), GLAA-C helped these cities in the Great Lakes region to increase their understanding of climate change and implement adaptation strategies aimed at building more resilient communities. GLAA-C also worked with staff from Graham's ongoing Great Lakes Integrated Science and Assessment (GLISA) program, who provided important climate information and expertise. GLISA is a U.S. National Oceanic and Atmospheric Administration (NOAA)-funded partnership between the University of Michigan (U-M) and Michigan State University (MSU). The program is dedicated to collaborative research that connects the producers and users of climate information in order to improve decisions in the Great Lakes region. By describing examples of the iterative processes and outcomes developed with the partner cities, this paper provides an overview of key lessons learned through the GLAA-C project. We emphasize the importance of identifying community vulnerabilities before working with climate data, the value of starting with observed climate data to enable productive discussions, and the critical role of collaboration in successful adaptation efforts. Finally, we summarize the key principles that guide our ongoing work within the urban adaptation realm and offer strategies for replicating our approach in other communities and regions.

1. Boundary organizations are agencies that inhabit a common space between intersecting worlds. One of their primary functions in this space is to broker information between these worlds in an adaptable and relevant way while still remaining robust enough to claim the common ground they inhabit (Lynch, Tryhorn, and Abramson 2008; Kalafatis et al. 2014). Boundary organizations often translate complex information, such as climate science, into an accessible and user-friendly format for specific end-users of the information, such as policy makers. 
is critical to helping it overcome resource constraints and assisting it in decision processes.

In addition to these specific lessons, three broader themes emerged over the course of the project. These themes now drive how the U-M Climate Center (a recently established center at the Graham Sustainability Institute) interacts with communities and practitioners while assisting them with adaptation planning.

\section{Community-informed vulnerability discussions first, local climate data second}

When the GLAA-C project team set out to assist decision makers in integrating climate adaptation efforts into their ongoing plans and policies, it became clear that community-informed vulnerability discussions are an important first step in the process. We need to understand a community's existing vulnerabilities, resources, needs and values before we can apply local climate data to any adaptation planning process. Because the impacts of climate change are not equally distributed nor evenly experienced across different populations within a community, candidly discussing existing vulnerabilities and weaknesses in infrastructure and service delivery helped ensure that those most at risk were the first priority. Factors that can influence how severely climate impacts a community include land use (especially as it relates to the amount of impervious surface versus vegetative cover), demographic characteristics like poverty and age, age and condition of infrastructure, and topography like low-lying areas and steep gradients (Baule et al. 2014). While many of these data can be gathered using remote sensing, land cover data sets, census information, and other standardized data tools, we found that simply speaking directly with community members was the best way to learn how potential risks or resources have converged to prevent or create problems areas. Their personal experiences provide critical insight into a city's social, economic, and infrastructural strengths and vulnerabilities, beyond what any map or dataset could provide. We also found that engaging community members in a vulnerability discussion or exercise at the beginning of the adaptation process provided important local context and helped move the planning process more quickly towards relevant, place-based strategies that were likely to be implemented.

In our initial interactions with partner cities, we began meetings with a lengthy, in-depth presentation about climate change. It included an overview of both observed and projected climate changes for the Great Lakes region, as well as a broad list of impacts experienced throughout the region. This approach had several un- 
intended consequences: participants sometimes felt overwhelmed and unsure of where to begin their adaptation efforts, participants sometimes lost interest in confronting climate change impacts, and ensuing discussions about appropriate adaptation strategies often focused on addressing climate change directly and were not grounded in the community's needs and experiences. We speculated that the scale of the problems presented and the long, generalized list of impacts did not align with the municipal problems and priorities decision makers and practitioners work with, which created a major obstacle from the onset of engagement. After these comprehensive presentations, efforts to make connections between Great Lakes climate change impacts and the city or community's adaptation planning process were complicated, tended to be unnecessarily long, and did not always result in the best place-based strategies.

After realizing that our approach was not as efficient or effective as we had hoped, we began to experiment with other engagement methods. The approach we ultimately developed engaged community members meaningfully and ensured that useful climate data were applied appropriately to adaptation planning efforts. This method featured a workshop or meeting that brought together key community stakeholders and decision makers. It typically began with a brief overview of observed climate change in the Great Lakes region, followed by a discussion about the impacts participants were already experiencing in their communities. They also identified areas that would be most impacted if the observed climate trends continued. Providing participants with a brief overview of the observed changes gave them an important point of reference for the ensuing discussion about impacts. Additionally, presenting historical data built trust, as it allowed project staff to share their research, to demonstrate their interest in the local experience, and to validate the experiences of meeting participants.

Moving the local vulnerability conversation to the beginning of the engagement process also significantly sped up our partner community's movement into developing and prioritizing place-based adaptation strategies. For example, on the second day of a large regional conference in Toledo, Ohio, GLAA-C staff facilitated a meeting between Toledo staff and stakeholders that focused specifically on how City of Toledo staff could address climate impacts and harness the energy of sustainability work in the greater region. The session began with a brief overview of historical climate changes, a review of adaptation strategies taking place in the region, and a recap of the potential climate impacts highlighted during Day 1 of the conference. After this presentation, GLAA-C staff facilitated a discussion on the following questions: 
- What programs, policies, or resources does your department currently have that will help it adapt to climate change?

- What does your department need in order to adapt to climate change?

-What actions are being taken to prepare for existing and projected climate related impacts?

-What mechanisms (e.g., existing plans, policies) are available to implement adaptation strategies?

- What actions are you, your department, other departments, or the city as a whole taking to prepare for existing and projected future climate related impacts to these systems?

Gathering staff and key stakeholders in a small setting and focusing on city resources and needs enabled the participants to have candid discussions about how to understand and prioritize climate impacts and risks. Since the discussion began with their experiences and knowledge, they felt more empowered to address the identified impacts. During this half-day session, it quickly became clear that dealing with increasing precipitation and stormwater was by far Toledo's most pressing concern. This early realization accelerated ensuing adaptation work in Toledo and helped the GLAA-C team customize the information and services it provided to Toledo. Subsequent support included a graduate student project focused on updating Toledo's stormwater credit program and a workshop later that year that focused specifically on managing stormwater in the northeast-Ohio, southeast Michigan region. This focus on precipitation impacts and flooding also propelled engagement with vulnerable populations and private-sector partners in flood-prone neighborhoods, which then adopted on-site stormwater management strategies to mitigate stormwater flooding and nuisance flooding.

\section{Observed climate data enables climate discussions to occur.}

Another theme that emerged over the course of the project was the valuable role of locally relevant observed (historical) climate data in opening the door to future climate conversations, which then enable climate information to become a part of decision-making processes. Despite overwhelming evidence and scientific consensus that climate change is occurring (Anderegg et al. 2010), climate change remains politically polarizing on the national level, and local municipal leaders (elected officials and staff) approach the subject with caution. In our experience, the topic was often perceived as politically charged and was therefore difficult for cities to tackle 
directly. To overcome these hesitations and engage decision makers in entry-point climate conversations, we used fact sheets about historical climate data that illustrated how climate has already changed in recent decades. Looking at the historical change often revealed that a city's existing standards and decision tools - such as intensity-duration-frequency curves (a precipitation tool that engineers use to determine appropriate sizing for gray infrastructure) — were based on outdated precipitation information and thus required reconsideration and revision. In addition, by beginning with observed changes that community members often confirmed with their own experiences, we were able to demonstrate a historical trend in the way the climate is changing. Across the Great Lakes region, these trends include rising temperatures and extended heat waves, as well as increases in the frequency and intensity of major storms (Great Lakes Integrated Sciences and Assessment 2014).

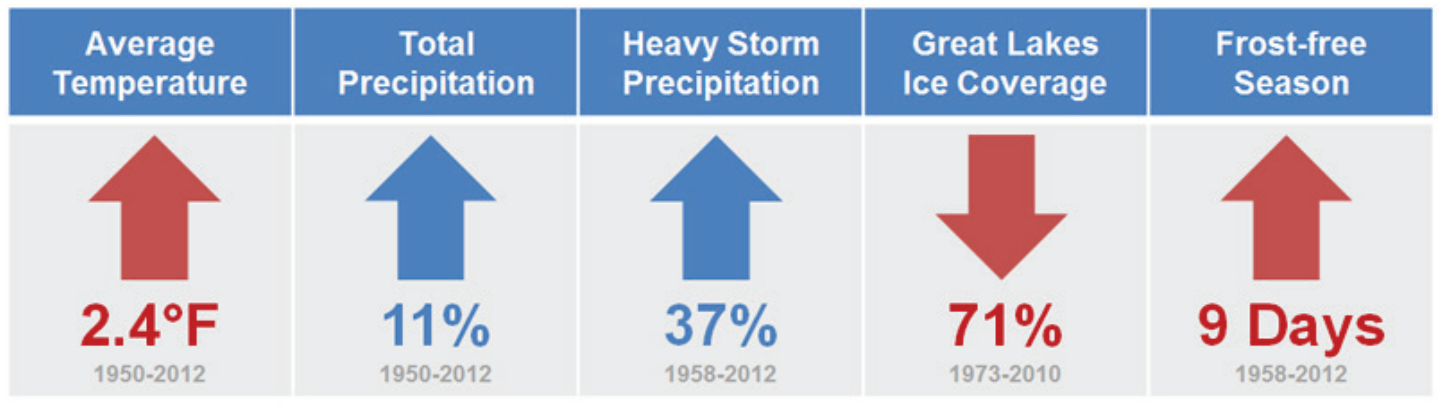

Figure 2. This figure demonstrates recent observed changes in the Great Lakes region. Using this type of historical information to demonstrate that the climate is already changing proved to be an important tool for obtaining buy-in from city practitioners.

Source: GLISA

Using historical climate data to open the door to climate discussions was particularly effective in our work with Ann Arbor, Michigan. The City of Ann Arbor experienced an average annual precipitation increase of $24 \%$ in the period of 1980 - 2010, as compared to 1950 - 1980. After learning about this stunning increase, city staff used the data to engage stormwater engineers, hazard mitigation planners, and public works administrators on the subject of climate change. This information also helped the city emphasize the need for immediate action and consideration of the size and type of infrastructure implemented in the City's capital projects. The City is now working to embed up-to-date climate information into planning and engineering processes, as evident in the February 2014 formation of a Technical Oversight Advisory Group to assist with the management of wet weather projects. 
An additional benefit of presenting observed trends to practitioners is that it often led to questions about what to expect in coming years. Thus, instead of the climate resource providers attempting to convince practitioners of climate projections, the practitioners and decision makers were themselves asking for these projections so that they could make more informed decisions moving forward.

We typically used two resources to present observed climate data to our city partners. The first was a summary of the city's nearest weather station's observed climate record. The climate stations we used to create the fact sheets are included in NOAA's quality-controlled Global Historical Climate Network-Daily (GHCNDaily) dataset. We selected only stations that had reliable, continuous observations of temperature and precipitation since 1951 for comparison of 30-year periods since then, though many stations have records from much earlier. Observational station recordings at specific locations over time are particularly useful for collecting extreme weather information on a daily basis, such as extreme rainfall and heat events. Information about extreme events is particularly useful to practitioners and emergency management planners, as most infrastructure is designed to withstand extreme events, rather than temperature or precipitation averages. We also used station records to identify long-term climate trends, with the caveat that they represent only trends in a specific place over time. The information any single station collects can be significantly influenced by the surrounding land use. For instance, if the station is located near dark urban surfaces, such as asphalt, warming temperature trends may be amplified.

In addition to providing local climatologies, we also provided climate records for multi-county areas known as climate divisions. Climate divisions are officially designated by NOAA and combine zones subject to similar climate drivers. The climate information represented by climate divisions is based on the aggregation of all the climate-station information collected throughout the division. This data is quality controlled, weighted, and interpolated throughout the area to accurately represent the measurements over the entire area. There are twenty-six climate divisions across the Great Lakes Basin. Drawing from multiple sources within a division better represents regional trends, since local factors that affect individual observational sites have limited impact on the overall trend of the division. The drawback of using climate division information alone is that daily extreme weather events cannot be described for an entire multi-county area; thus, climate division information is not as useful to emergency managers or engineers who want to prepare their systems to handle major events. Still, it can provide a contextual anchor for long-term climate trends for the immediate region, while station observations provide locally relevant 
extreme event information. Both resources proved to be critical tools in our work with practitioners and decision makers throughout the region and over the course of the GLAA-C project.

\section{Collaboration drives successful adaptation efforts.}

A third central theme that emerged through the GLAA-C project is the importance of multi-sector, multi-scale, and multi-departmental collaboration in adaptation planning and implementation. As a "threat multiplier" (Defense 2014), the impacts from climate change cut across jurisdictional, political, and industry boundaries. Adaptation solutions must do the same. Widespread collaboration is important not only because climate change affects so many different sectors, but also because collaboration helps diversify ideas, strengthens communication among stakeholders, and enables more efficient resource sharing.

Throughout our work with the six GLAA-C cities - and with the other cities across the region where we conducted additional workshops-the most exciting ideas emerged when representatives from diverse departments or sectors worked together. One example of effective collaboration comes from Ann Arbor, Michigan. In September 2013, Ann Arbor city staff met for a half day to discuss climate impacts on the city's service areas and how to prioritize climate-related concerns. This workshop brought together about forty staff and ten GLAA-C facilitators. Following a discussion about existing best practices at the City and an overview of existing and anticipated climate changes for the area, each table was asked to complete an icebreaker activity. Participants sketched out a series of concentric circles to illustrate how a key climate change would impact city services and infrastructure and require new services (a vulnerability exercise). By arranging the workshop participants at tables with representatives from a mix of service areas, the activity allowed staff to see how their department's actions would impact other departments and to learn about the function and response mechanisms of other service areas. Figure 3 presents one example of a resulting concentric circle. After the workshop, the circles were displayed at a central location in City Hall for several weeks, and staff members were encouraged to continue to contribute to them. This activity provided city staff with an opportunity to think outside of their own service areas, reflect on how intertwined their work is with other areas, and carry the lessons from the workshop back into their daily work. At a recent meeting with the City, the Environmental Coordinator told GLAA-C staff that even though the circles have been taken down, he often finds himself and other staff asking questions about how other departments 


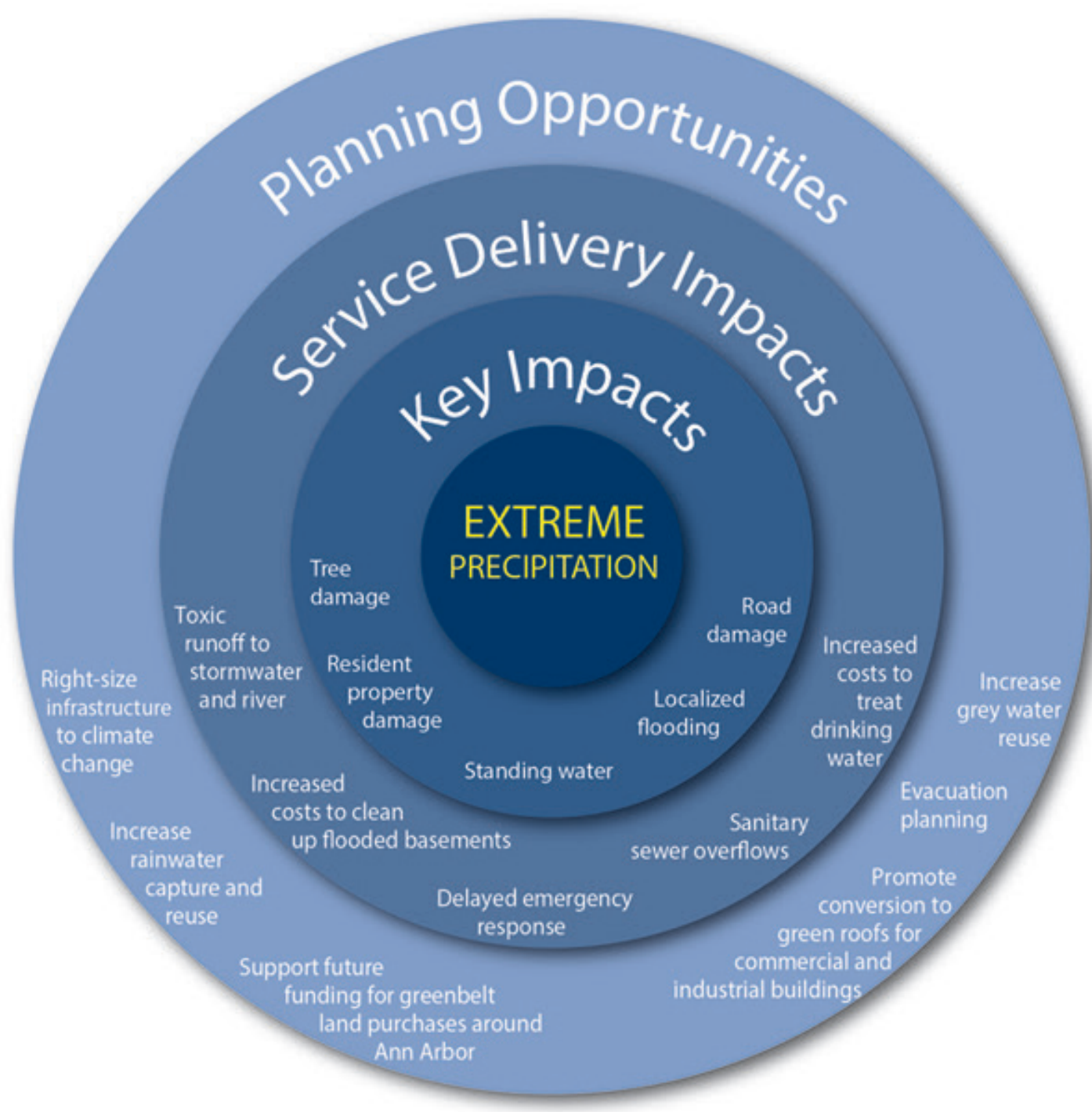

Figure 3. This is an example of the concentric circle exercise that the City of Ann Arbor participated in. This circle addresses the climate change impact of extreme precipitation. 
will be involved in a proposed project, what the cross-departmental impacts will be, and where opportunities for collaboration might exist.

Another example of innovative collaboration between diverse actors comes from Dayton, Ohio. Throughout its engagement with the GLAA-C project, the City of Dayton took a big-tent approach to thinking about climate risks. Its initial team included six participants representing Planning Development, Environmental Services, Economic Development, the Water Department, the Mayor's Office, and Aviation. Over thirty people attended a GLAA-C scoping meeting at the City of Dayton, including representatives from local colleges and universities, watershed groups, regulatory agencies, the airport, and numerous city departments. As a result, collaborations formed between departments and agencies that-despite their limited resources-would not typically work together to build strong responses. During one meeting, representatives from the county health department, the Regional Air Pollution Control, the Area Agency on Aging, and the City Communications Department realized that by pooling their expertise and resources, they could more effectively help at-risk populations during heat events.

Discussions on climate change adaptation not only lead to innovative partnerships but also expand opportunities for communication between unlikely allies and partners. One such example comes from the City of Toledo, where the GLAA-C project connected the City with a team of urban planning graduate students who helped it refine and re-launch its stormwater credit manual. The students helped the City identify priority areas where it would incentivize on-site stormwater management approaches through its stormwater credits. They zeroed in on four specific zones that had a combination of vulnerability factors, including low-lying topography that made them susceptible to regular flooding events, lack of improved streets, a high percentage of low-income people and people of color who cannot always afford preventive measures, and connection to the remaining combined sewer system. Many of these zones were also home to large manufacturing sites. The City recognized the opportunity to engage private-sector partners in the targeted stormwater efforts and began working with three specific companies. These companies' on-site stormwater management practices would not only significantly reduce their contribution to the stormwater system in these vulnerable priority zones but would also set an example for other major industrial facilities throughout the city to follow. Engaging with the urban planning students helped city staff recognize an opportunity to serve at-risk neighborhoods by engaging influential private partners in their green infrastructure efforts.

Another example of unlikely adaptation partnerships occurred in Kingston, On- 
tario. When Kingston applied to participate in the GLAA-C program, it was already a leader in sustainability and well on its way to building a strong climate adaptation program. GLAA-C helped Kingston take its sustainability efforts further by providing small grant funding, allowing the city to connect with a number of ongoing initiatives. By leveraging the GLAA-C funds, the City of Kingston partnered with and received matched funding from the Royal Bank of Canada to carry out a treeplanting campaign at its city bus stops, a project aimed at improving air quality and providing shade for commuters in low-income areas. Kingston also used GLAA$\mathrm{C}$ funding to connect with the public school system to develop and distribute a climate change education tool-kit to elementary school teachers. In collaboration with the City, the teachers had their students create a public art display of pictures showing what children valued about their current environment. These images were displayed across the central city marketplace. In a third GLAA-C funded initiative, city staff partnered with a regional public health agency team at Queens University in order to incorporate climate information into the GIS map layers used during emergency responses. While the groundwork for each of these efforts may have been in place prior to our engagement, GLAA-C project funding and guidance helped these unique and effective collaborations come to fruition.

\section{Moving beyond the Great Lakes region}

\section{Replicating our approach across regions and sectors}

Over the last several years, the climate adaptation field has grown significantly, and a great many resources and tools designed to assist practitioners have emerged(Dietz and Bidwell 2011; Winkler et al. 2014; Lemos et al. 2012; Lemos, Kirchoff, and Ramparasad 2012). A 2012 survey of adaptation in the Great Lakes region identified over 200 case studies covering nearly every sector and a range of scales: local, state, regional, and transboundary (Gregg et al. 2012). A 2014 survey focusing specifically on tools and resources for municipal decision makers uncovered over 3,400 resources nationally (Stults et al. 2015). While the findings from these surveys make it clear that an increasing number of resources exist to support climate adaptation efforts, we have also found that the guiding principles of our ongoing approach are needed to support climate work in our region and beyond. Drawing on a review of work by Gregg (Gregg et al. 2012),Stults (Stults et al. 2015), our own surveys and engagements, and the findings from a number of regional climate adaptation 
conferences over the past year, we identify these key principles and offer guidance for replicating our approach in other regions.

- Ongoing translation- Understanding how climate change will impact specific stakeholder groups and communities still requires translational services similar to those provided through the GLAA-C project. As more people engage in climate discussions, they need relevant climate information from a trusted source, in an accessible and useful format.

- Flexibility - As the field of adaptation rapidly expands and evolves, it is essential to provide resources that match the diverse needs of people across a broad spectrum of the climate discussion.

- Guidance through downscaling discussions- Because the region's topography is relatively uniform and there is less climatic diversity at small spatial scales, downscaled models have diminished utility in the region. Additionally, regional lake-land climate interactions are not well understood; this makes direct application of climate projections difficult and complicates the framing of uncertainty. In general, downscaled data brings with it a number of complicated concepts, including an increase in uncertainty. Thus, guidance on this issue is critical when working with municipalities that want to base their actions on locally relevant climate data.

- Guidance through uncertainty- Users need to be guided through discussions of uncertainty and helped to feel empowered to act in the face of that uncertainty.

- Strong collaborations and partnerships - All of this work requires strong partnerships and collaborations. As more agencies, organizations, and private firms enter the climate adaptation field, it is imperative that we work collaboratively by sharing tools and resources, be aware of each other's strengths, and be willing to point end users to the best resources available, wherever they may come from. NOAA's Administrator calls this the "No wrong door policy."

While the Great Lakes region certainly has unique geographic, economic, and cultural characteristics, the lessons we describe above are highly applicable to other regions. In addition, these approaches to engagement and information integration can easily be adopted by sectors outside of municipal work. The Urban Adaptation program at the University of Michigan's Climate Center integrates many of the lessons learned through the GLAA-C project when it works with new cities and partners. 


\section{Conclusion}

The GLAA-C project aimed to develop an approach to providing municipal decision makers throughout the Great Lakes region with the climate information and resources they need to move adaptation action forward in their communities. The iterative, multi-disciplinary, integrated assessment provided a theoretical and applied science framework to meet that goal. In addition to the three lessons described in this paper, a fourth lesson emerged: there is no one-size-fits-all solution to climate change adaptation. Rather, it takes locally relevant, tailored support and a deep commitment to understanding the unique characteristics, opportunities and challenges each community faces. Through this deliberate collaboration, the cities we partnered with have all advanced adaptation efforts and are continuing to do so even after our in-depth engagement has ended.

By building on the lessons learned through the GLAA-C project, the work of the University of Michigan Climate Center is enhancing and expanding its urban adaptation portfolio. Our goal, to build a resilient network of climate-ready communities, requires scaling our efforts in multiple ways. While we believe that our program benefits tremendously from including new municipalities in our network, adding cities one by one is not enough to truly scale the lessons we have learned. To scale these ideas of translation, guidance, and localization, we are also identifying ways to build new networks that include community-based organizations, climate service providers, and government agencies at multiple levels. In this sense, scaling across scales will not only allow lessons to transfer more quickly to new cities, but will also build resilience at the grassroots level and inspire the state- and federal-level policy changes necessary for sustained progress.

The integrated assessment model of the GLAA-C project lends itself to this diverse scaling approach. The flexibility to meet the problem where it is allows us to customize our tools and resources to match user needs.

\section{References}

Altman, P. 2012. Killer Summer Heat: Projected Death Toll from Rising Temperatures in America Due to Climate Change. NRCD Issue Brief. Natural Resources Defense Council.

Anderegg, W., J. Prall, J. Harold, and S. Schneider. 2010. "Expert Credibility in Climate Change.” PNAS 27: 12107-12109.

Baule, W., L. Briley, D. Brown, and E. Gibbons. 2014. Synthesis of the Third National Climate 
Assessment for the Great Lakes Region. Ann Arbor: Great Lakes Integrated Sciences and Assessment.

Bidwell, D., T. Dietz, and D. Scavia. 2013. "Fostering Knowledge Networks for Climate Adaptation." Nature: Climate Change 3:610-611.

Bulkeley, H. 2013. Cities and Climate Change. London: Routledge.

Defense, United States Department of. 2014. "2014 Climate Change Adaptation Roadmap.” Alexandria: Office of the Deputy Under Secretary of Defense for Installations and Environment.

Dietz, T., and D. Bidwell. 2011. Climate Change in the Great Lakes Region: Decision Making Under Uncertainty. East Lansing: Michigan State University Press.

Dilling, L., and M. Carmen Lemos. 2011. "Creating Usable Science: Opportunities and Constraints for Climate Knowledge Use and Their Implications for Science Policy." Global Environmental Change 21 (2). doi:10.1016/j.gloenvcha.2010.11.006.

Great Lakes Adaptation Assessment for Cities. 2012. "Public Perceptions and Attitudes Toward Climate Change: Survey Fact Sheet.” Ann Arbor: GLAA-C, Graham Sustainability Institute.

Great Lakes Integrated Sciences and Assessment. 2014. "Climate Change in the Great Lakes Region, Executive Summary Fact Sheet." Ann Arbor: GLISA.

Gregg, R. M., K. M. Feifel, J. M. Kershner, and J. L. Hitt. 2012. The State of Climate Change Adaptation in the Great Lakes Region. Bainbridge Island: EcoAdapt.

Guston, D. H. 2001. "Boundary Organizations in Environmental Policy and Science: An Introduction." Science, Technology, and Human Values 26 (4): 399-408.

Kalafatis, S., C. Kirchhoff, M. C. Lemos, D. Scavia, and R. Rood. 2014. "Moving Climate Information off the Shelf: Boundary Chains and the Role of RISAs as Adapative Organizations." .

Kirchoff, C., M. Carmen Lemos, and S. Dessai. 2013. "Actionable Knowledge for Environmental Decision Making: Broadening the Usability of Climate Science.” Annual Review of Environment and Resources 38:393-414.

Lemos, M. C., C. Kirchhoff, S. E. Kalafatis, D. Scavia, and R. B. Rood. 2012. "Moving Climate Information off the Shelf: Boundary Chains and the Role of RISAs as Adaptive Organizations." Weather, Climate, and Society 6:273-285.

Lemos, M. C., C. Kirchhoff, and V. Ramparasad. 2012. "Narrowing the Climate Information Usability Gap.” Nature: Climate Change 2:789-794.

Lund, K., K. Dinse, J. Callewaert, and D. Scavia. 2011. "Benefits of Using Integrated Assessment to Address Sustainability Challenges." Journal of Environmental Studies and Sciences 1 (4): 289-295.

Lynch, A. H., L. Tryhorn, and R. Abramson. 2008. "Working at the Boundary: Facilitating Interdisciplinarity in Climate Change Adaptation Research.” Bulletin of the American Meteorological Society 89:169-179.

Rosenzweig, C., W. Solecki, S. Hammer, and S. Mehrotra. 2001. Climate Change and Cities: First Assessment Report of the Urban Climate Change Research Network. Cambridge: Cambridge University Press.

Stults, M., J. Nordgren, S. Meerow, R. Jacobson, M. Ongun, and C. Hamilton. 2015. "Assessing the Tools, Resources, and Services Available to Support Local Climate Adaptation in the U.S." Unpublished.

Winkler, J. J., J. A. Andresen, J. A. Hatfield, D. Bidwell, and D. Brown. 2014. Climate Change in the Midwest: A Synthesis Report for the National Climate Assessment. Washington, D.C.: Island Press. 